\title{
Assessment Long Term Effect of Mobile Phone Usage on Hearing Faculties Using Brainstem Evoked Response Audiometry
}

\author{
Gaurav Sharma ${ }^{1 *}$, Agrawal DK ${ }^{1}$, Hasan SA ${ }^{2}$ and Sneh Chauhan ${ }^{2}$ \\ ${ }^{1}$ Department of Physiology, Jawaharlal Nehru Medical College, Aligarh Muslim University, Aligarh, Uttar Pradesh, India 202002 \\ ${ }^{2}$ Department of Otorhinolaryngology, Jawaharlal Nehru Medical College, Aligarh Muslim University, Aligarh, Uttar Pradesh, India 202002
}

*Corresponding author: Gaurav Sharma, Department of Physiology, Jawaharlal Nehru Medical College, Aligarh Muslim University, Aligarh. U.P. India. 202002, Tel: +91 7417574751; E-mail: drgauravsharma.jnmc@gmail.com

Received date: June 14, 2016; Accepted date: July 20, 2016; Published date: July 25, 2016

Copyright: @ 2016 Sharma G, et al. This is an open-access article distributed under the terms of the Creative Commons Attribution License, which permits unrestricted use, distribution, and reproduction in any medium, provided the original author and source are credited.

\begin{abstract}
Mobile phones are the necessity in modern life. The exposure to electromagnetic field emitted by mobile telephones is increasing rapidly that causes side effects, which may be thermal and non-thermal side effects. Thirty non-user participants and sixty user participants (who use mobile phones for more than 1 hour for more than 2 years) were included in the study. Users participants were further sub-divided into Group A (which use mobile phones for more than 1 hours for more than 2 years but less than 5 years) and Group B (who use mobile phones for more than 1 hours for more than 5 years). Auditory status of the subjects was assessed by Brainstem Evoked Response Audiometry (BERA). Latencies of waves I, III, V and inter-peak latency of I-V were recorded in users and non-users. There was a significant change in the latencies of BERA potentials of wave I and III in users compared to non-users. These changes suggest that radiations emitted from mobile phone causes damage to inner ear, cochlea and may be outer hair cells of inner ear. These results show that electromagnetic frequencies of mobile phone cause some damage to ear and auditory pathway. The study shows that mobile phones have a detrimental effect on the human auditory system.
\end{abstract}

Keywords: Mobile phones; Brainstem evoked response audiometry; BERA; Electromagnetic radiations

\section{Introduction}

Mobile phones have become a necessity in human day to day life. Mobile phones are regarded as a pivotal instrument for an individual to remain informed and connected with the outside world. Mobile phones are used to make and receive calls, which in turn receive and emit electromagnetic radiation [1]. These electromagnetic radiations are absorbed by the body. These radiations are proven to be harmful to different organ systems of human body. More so, the amount of damage is directly proportional to the amount of exposure to these radiations. The exposure to electromagnetic radiations causes side effects, including thermal and non-thermal side effects. Sensations of burning or warmth around the ear [2], headache [3], disturbance of sleep [4], alteration of cognitive functions and neural activity $[5,6]$, as well as alteration in the blood-brain barrier and a change in the regional cerebral blood flow have been reported as effects resulting from mobile phone usage $[7,8]$. Ill effects of electromagnetic radiations on humans are rightly assumed as the matter of serious public health concern. Therefore, any detrimental biological effect(s) related to mobile phone use should be considered as a high-priority health issue and a potential matter of scientific discussion.

Needless to mention, due to the close proximity of mobile phones to the ear, there can be potential damage to the auditory functions [9].

To evaluate the functional status of auditory nerve and brainstem auditory sensory pathway, Brainstem Evoked Audiometry Response (BERA) is a simple and effective technique. It is a non-invasive and reproducible method that is easy to administer and requires minimal co-operation of the patient and measures the specific relevant functions of the auditory pathway. Besides, it is not significantly affected by the state of consciousness, drugs and a variety of environmental factors including other sensory inputs to the cortex [10]. BERA is therefore widely used as an objective diagnostic tool in modern neurophysiology in this context. The electrical responses from BERA include several waves which in turn reflect the neural conduction velocity at corresponding levels of the auditory brainstem.

Also, there is very limited data available about the effect of long term use of mobile phones on ears and its assessment by BERA. Thus, this study is aimed and designed to bridge the existing knowledge gaps and investigate the practical utility of BERA in the assessment of impact of mobile phone usage on auditory function.

\section{Material and Methods}

Sixty participants (mobile phone users) and thirty participants (non-users) were recruited for the study. The users were asked about the use of mobile phones by right ear or left ear. Most of the users reported use of only one ear throughout the call, consistently. Those users who reported equal use of both ears were excluded from the study. Though the number of users and non-users in the study is unequal but the total number of radiation exposed ears and total number of unexposed ears (two ears per non-user) is equal. As nonuser participants have not used mobile phone from any ear.

User group: Sixty healthy participants of age group 18-40 years were taken in this group. They were further divided into two sub groups. They were as under:

Group A: Thirty participants using mobile phone for more than two years but less than five years and for more than one hour per day. 
Page 2 of 4

Group B: Thirty participants using mobile phone for more than five years and for more than one hour per day were included in this group.

Non-user group: Thirty participants who were not currently using mobile phones OR only seldom used mobile phones, i.e., less than 10 min per day for less than one year were grouped in non-user group.

User participants were recruited from among males and females in the age group of 18-40 years. The user participants were adults in the specified age groups using mobile phones for not less than two years duration. The participants chosen had good general health without any known medical conditions or any significant past medical (diabetes and hypertension) or psychiatric history. There was no history of otalgia, discharging ear, ear surgery, any history or diagnosis of head and neck tumour(s) or any other known otological diagnosis. There was no history of prolonged usage of ototoxic drugs among them.

Non-user participants chosen were age matched with the above mentioned inclusion criteria. The non-user participants also had no significant medical history and were free from any clinically apparent ear complaint(s).

The information regarding the use of handsfree devices, duration of use and exposure time per day, use of which ear predominantly (left ear or right ear) and medical and/or otological morbidities were recorded. Duration for which handsfree set was used was deducted from the total duration of usage. Eligible subjects fulfilling the inclusion criteria were then subject to BERA.

BERA was performed by NEUROPERFECT apparatus by MEDICAID INDIA (Chandigarh). BERA was performed on the dominant ear using the vertical montage electrode on high forehead (positive electrode). The mastoid process was chosen for reference right and left electrodes and low forehead region served as the site for the ground electrode.

BERA was done only in the dominant ear (ear with which people used to talk over mobile phone for most of the time) among user group. In the non-user group, testing was done in both the ears, as they have not used mobile phones from either ear.

BERA was done at $70 \mathrm{~dB}$ frequencies and 2000 clicks (alternating type) were given and average of all the clicks recorded. Each reading was recorded twice for reproducibility and to minimize artefacts in the recording. The stimulus type was clicks with a repetition rate of 11.6/s.

Peak ABR latencies (I, III and V) were recorded and inter-peak interval I-V was calculated digitally [11-13].

Informed consent of each participant was taken prior to the study. Clearance was taken from the institutional ethical committee.

\section{Data Analysis}

Data analysis was done using the SPSS software version 22.0. BERA waves and inter-peak latencies in users and non-users were compared using the Student Paired t-test. Probability (p) value of less than 0.05 was considered statistically significant.

\section{Results}

Comparison between the age of non-users and all users (group A +group B) shown in Tables 1-4.

\begin{tabular}{|l|c|c|c|c|}
\hline & $\begin{array}{l}\text { Non- } \\
\text { users }\end{array}$ & $\begin{array}{l}\text { Users } \\
\text { (Total) }\end{array}$ & $\begin{array}{l}\text { Users group } \\
\text { A }\end{array}$ & $\begin{array}{l}\text { Users group } \\
\text { B }\end{array}$ \\
\hline No. of individuals & 30 & 60 & 30 & 30 \\
\hline $\begin{array}{l}\text { Average Age (in } \\
\text { years) }\end{array}$ & $26.1 \pm 4.7$ & $25.7 \pm 3.9$ & $24.8 \pm 3.8$ & $26.6 \pm 3.7$ \\
\hline
\end{tabular}

Table 1: Depicts the baseline characteristics of users and non-users. The average ages of users $(25.7+3.9$ years $)$ and non-users $(26+4.7$ years) were largely comparable. The average age of users in group $\mathrm{A}$ was $24.8+3.8$ years and that in group B was $26.6+3.7$ years.

\begin{tabular}{|l|c|c|c|}
\hline Parameter & Non-users & Users (Group A+Group B) & P value \\
\hline Wave I & $1.521 \pm 0.185$ & $1.602 \pm 0.226$ & $<0.05$ \\
\hline Wave III & $3.745 \pm 0.216$ & $3.842 \pm 0.264$ & $<0.05$ \\
\hline Wave V & $5.623 \pm 0.218$ & $5.681 \pm 0.291$ & $>0.05$ \\
\hline IPL I-V & $4.102 \pm 0.310$ & $4.079 \pm 0.287$ & $>0.05$ \\
\hline Sample size & 60 & 60 & \\
\hline
\end{tabular}

Table 2: Comparison between the results of BERA at $70 \mathrm{~dB}$ between non-users and total users (Group A+Group B).

It shows a significant prolongation of latencies of wave I and wave III of total users (Group A+Group B) in comparison to non-users $(\mathrm{p}<0.05)$. Latency of waves $\mathrm{V}$ and inter-peak latency I-V did not show significant statistical difference in comparison to non-users ( $p>0.05)$.

\begin{tabular}{|l|c|c|c|}
\hline Parameter & \multicolumn{1}{|l|}{ Non-users } & \multicolumn{1}{|l|}{ User Group A } & P value \\
\hline Wave I & $1.521 \pm 0.185$ & $1.594 \pm 0.235$ & $>0.05$ \\
\hline Wave III & $3.745 \pm 0.216$ & $3.836 \pm 0.297$ & $>0.05$ \\
\hline Wave V & $5.623 \pm 0.218$ & $5.666 \pm 0.284$ & $>0.05$ \\
\hline IPL I-V & $4.102 \pm 0.310$ & $4.072 \pm 0.276$ & $>0.05$ \\
\hline Sample size & 60 & 30 & \\
\hline
\end{tabular}

Table 3: Comparison of results of BERA at $70 \mathrm{~dB}$ between non-users and user group A.

This table depicts the latencies of waves I, wave III and wave V. Inter-peak latency $\mathrm{I}-\mathrm{V}$ did not reveal any significant statistical difference in users as comparison to non-users ( $\mathrm{p}>0.05)$.

\begin{tabular}{|l|c|c|c|}
\hline Parameter & \multicolumn{1}{l|}{ Non-users } & User Group B & P value \\
\hline Wave I & $1.521 \pm 0.185$ & $1.610 \pm 0.219$ & $<0.05$ \\
\hline Wave III & $3.745 \pm 0.216$ & $3.849 \pm 0.233$ & $<0.05$ \\
\hline Wave V & $5.623 \pm 0.218$ & $5.697 \pm 0.301$ & $>0.05$ \\
\hline IPL I-V & $4.102 \pm 0.310$ & $4.086 \pm 0.302$ & $>0.05$ \\
\hline Sample size & 60 & 30 & \\
\hline
\end{tabular}

Table 4: Comparison of results of BERA at $70 \mathrm{~dB}$ between non-users and user group $\mathrm{B}$. 
This table shows statistically significant prolongation of latencies of wave I and wave III of users Group A in comparison to non-users $(\mathrm{p}<0.05)$. Latency of waves $\mathrm{V}$ and inter-peak latency I-V however did not show any statistically significant difference in comparison to nonusers $(\mathrm{p}<0.05)$.

\section{Discussion}

Mobile phones have become a part of modern life style. There has been a rapid boom in the number of mobile phones in the recent decade. This rapid worldwide expansion of mobile telephones raises questions regarding possible effects of the emitted radiofrequencies on the health of the consumers.

Brain stem evoked response audiometry or BERA is an important non-invasive technique to access the functioning of auditory pathway. As the assessment of brainstem function is difficult by other conventional techniques. It encompasses diagnosis of lesion ranging from VIII cranial nerve to the auditory cortex and is based upon the study of electrical potentials generated by the auditory pathway in response to external stimuli by means of surface electrodes over scalp.

In the present study, comparing the latencies of wave I, III, $\mathrm{V}$ and interpeak latency of $I-V$ of non-users $(n=60)$ to total users $(n=60)$, it was observed that latencies of wave I and wave III were significantly increased in total users, and attained statistical significance.

The latencies of wave I, III, V and interpeak latency of I-V of nonusers $(n=60)$, when compared to user group $A(n=30)$. It was observed that none of the parameters were increased to the extent to exhibit statistically significance in users group A.

While comparing the latencies of the non-users $(n=60)$ and user group B $(n=30)$, latencies of wave I, III, V and interpeak latency of I-V, it was seen that latencies of wave I and wave III were significantly increased in users. The same assumed statistical significance.

Oktay MF et al. [14] studied the effects of mobile phones on hearing by pure tone audiometry and brainstem evoked audiometry response. Interpeak latencies of I-V, I-III, III-V were studied. No significant difference was reported in the interpeak latencies in users and nonusers in their study.

Davidson et al. [15] studied the effects of chronic mobile phone usage on hearing, and reported that there is no harmful effect of mobile phone usage on their audiovestibular systems within the range of exposure of the study.

Counter et al. [16] investigated the effect of long-term transcranial electromagnetic stimulation on the auditory brainstem and cortical evoked responses over a period of 12 months in rabbits. The difference in the amplitude and the latency of wave III was observed. The amplitude and latency of the other waves showed no significant changes before and after exposure. Subsequent histological examination of the cochlear nucleus and inferior bigeminal bodies revealed no structural and morphological changes.

Kellenyi et al. [17] reported that pulsed EMF emitted by a cellular phone for 15 min caused a $0.2 \mathrm{~ms}$ delay in the wave V of ABR.

Kaprana et al. [18] studied the time related changes in auditory pathway during mobile phone electromagnetic exposure in rabbits. In their study they reported that absolute latency of wave III, and interpeak latencies of I-V and III-V were significantly prolonged after exposure to electromagnetic frequencies in a time dependent manner.
Shilpakhullar et al. [19] studied the effects of electromagnetic frequencies generated by mobile phones (GSM) on auditory brainstem response. They reported that latencies of wave $\mathrm{I}$ to $\mathrm{V}$ as well as interpeak latency of wave I-V, I-III and III-V were significantly increased in individuals using mobile phones for $30 \mathrm{~min} /$ day for 10 years.

In many studies it has been shown that short term exposure to electromagnetic frequencies (few minutes) did not prolong the latencies of waves of ABR.

In our study, we found significantly increased latencies of wave I and III in total users and in Group B. Different waves of BERA correspond to different parts of auditory pathway. Latency of Wave I is increased when there is damage to auditory nerve or there is a cochlear pathology. Electromagnetic frequencies of mobile phones cause damage to nerves [20]. Since, auditory nerve is closest to electromagnetic field of mobile phone; it is the most likely nerve to be damaged. Therefore, damage to the auditory nerve due to EMF could possibly be the reason behind increased latency of wave I.

Electromagnetic frequencies emitted from mobile phones causes increased incidence of brain tumour and acoustic neuroma [21]. There is significant increase in occurrence of acoustic neuroma in persons using mobile phones for more than 10 years [22]. In our study, there was an increased latency of Wave III in total users and in user Group B. Wave III originates from cochlear nucleus, which is present at cerebellopontine angle. EMF are also known to cause acoustic tumour in persons using cell phones for more than 10 years, and most common site for acoustic neuroma is cerebellopontine angle. This may be the reason, due to location [23] the neuron tissue damage that occurs is due to exposure to electromagnetic frequency of mobile phones. Also, the same may be the reason for increased latency of wave III, much before the damage is enough to cause the tumour.

\section{Conclusion}

On comparison between latencies of BERA in total user ears $(n=60)$ and non-user ears $(n=60)$, a significant increase in the latencies of the wave I and wave III was observed. Similar results were seen when Group B users were compared to non-users. Group A had no significant change in latency of any the wave. The results show that there is definite damage to neurons exposed to electromagnetic radiations. Thus from this study we conclude that, electromagnetic radiations of mobile phones have detrimental effects on human auditory functioning. Further, the damage to the ear is proportional to the amount of exposure.

However, amount of damage and safety limit for use of mobile phones cannot be effectively extrapolated from this study alone and future prospective research in required to define the safe hours of use and to reduce the emissions of these radiations from mobile phones.

\section{References}

1. Ali Zamanian, Hardiman CY (2005) Electromagnetic radiation and human health: A review of sources and effects, EMR \& HUMAN HEALTH pp. 16-26.

2. Oftedal G, Wilen J, Sandstrom M, Mild KH (2000) Symptoms experienced in connection with mobile phone use. Occup Med (Lond) 50: 237-245.

3. Frey AH (1998) Headaches from cellular telephones: Are they real and what are the implications? Environ Health Perspect 106:101-103. 
Citation: Sharma G, Agrawal DK, Hasan SA, Chauhan S (2016) Assessment Long Term Effect of Mobile Phone Usage on Hearing Faculties Using Brainstem Evoked Response Audiometry. J Neurol Neurophysiol 7: 387. doi:10.4172/2155-9562.1000387

Page 4 of 4

4. Borbely AA, Huber R, Graf T, Fuchs B, Gallmann E, et al. (1999) Pulled high-frequency electromagnetic field affects human sleep and sleep electroencephalogram. NeurosciLett 275: 207-210.

5. Preece AW, Iwi G, Davies-Smith A (1999) Effect of a $915 \mathrm{MHz}$ simulated mobile phone signal on cognitive function in man. Int J RadiatBiol 75:447-456

6. Hamblin DL, Wood AW, Croft RJ, Stough C (2004) Examining the effects of electromagnetic fields emitted by GSM mobile phones on human event-related potentials and performance during an auditory task. Clinical Neurophysiology 115: 171-178.

7. Fritze K, Sommer C, Schmitz B (1997) Effect of global system for mobile communication (GSM) microwave exposure on blood-brain barrier permeability in rat. Acta Neuropathol 94: 465-470.

8. Haarala C, Aalto S, Hautzel H, Julkunen L, Rinne JO, et al. (2003) Effects of a $902 \mathrm{MHz}$ mobile phone on cerebral blood flow in humans: A PET study. Neuroreport 14: 2019-2023.

9. Al-Dousary SH (2007) Mobile phone induced sensorineural hearing loss. Saudi Medical Journal 28: 1283-1286.

10. Coats AC, Martin JL (1977) Human auditory nerve action potentials and brain stem evoked responses. Arch Otolaryngol 103: 605-622.

11. Chiappa $\mathrm{KH}$, Ropper $\mathrm{AH}$ (1982) Evoked potentials in clinical medicine. New England Journal of Medicine 305: 1140-1150.

12. Courjon J, Mauguiere F, Revol M (1982) Clinical applications of evoked potentials in neurology. Advances in neurology 32: 1-9.

13. Stockard JJ, Stockard JE, Sharborough FW (1977) Detection and localization of occcult lesions with brainstem auditory responses. Mayo Clinic Proceedings 52: 761-767.

14. Oktay MF, Dasdag S (2006) Effects of intensive and moderate cellular phone use on hearing function. Electromagnetic and Biological Med 25 13-21.
15. Davidson HC, Lutman ME (2007) Survey of mobile phone use and their chronic effects on the hearing of a student population. International Journal of Audiology 46: 113-118.

16. Counter SA (1993) Neurobiological effects of extensive transcranial electromagnetic stimulation in an animal model. Electroencephalogram Clinical Neurophysiology 89: 341-348.

17. Kellenyi L, Thuroczy G, Faludy B, Lenard L (1999) Effects of mobile GSM radiotelephone exposure on the auditory brainstem response (ABR). Neurobiology 7: 79-81.

18. Kaprana AE, Chimona TS, Papadakis CE, Velegrakis SG, Vardiambasis IO, et al. (2011) Auditory brainstem response changes during exposure to GSM-900 radiation: An experimental study. Auditory Neurotology 16: 270-276.

19. Khullar S, Sood A, Sood S (2013) Auditory brainstem responses and EMFs generated by mobile phones. Indian J Otolaryngol Head Neck Surg 65: S645-S649.

20. Salford LG, Brun AE, Eberhardt JL, Malmgren L, Persson BR (2003) Nerve cell damage in mammalian brain after exposure to microwaves from GSM mobile phones. Environ Health Perspect 111: 881-883.

21. (2004) INTERPHONE study, Mobile phone use and acoustic neuroma, IARC (International Agency for Research on Cancer). World Health Organisation (WHO).

22. Hardell L, Carlberg (2009) MMobile phones, cordless phones and the risk for brain tumours. Int J Oncol 35: 5-17.

23. Klose AK, Sollmann WP (2000) Anatomical variations of landmarks for implantation at the cochlear nucleus. J LaryngolOtol 27: 8-10. 